\title{
Accuracy Evaluation of GlucoLAB Auto-coding and Finetest Lite Glucose Monitoring Systems Following ISO 15197:2013
}

\author{
Kyungso Jeon ${ }^{1}$ and \\ Miseon Shin ${ }^{2}$ \\ ${ }^{1}$ Department of Laboratory \\ Medicine and ${ }^{2}$ Division \\ of Endocrinology and \\ Metabolism, Hanil General \\ Hospital, Seoul, Korea \\ Corresponding author: \\ Kyungso Jeon \\ Department of Laboratory \\ Medicine, Hanil General \\ Hospital, 308 Uicheon-ro, \\ Dobong-gu, Seoul 01450, Korea \\ Tel: +82-2-901-3720 \\ Fax: +82-2-901-3606 \\ E-mail: jks3393@hanmail.net \\ pISSN: $2384-2458$ \\ elSSN: 2288-7261
}

Received June 29, 2016, Revision received July 14, 2016, Accepted July 21, 2016
There are several evaluating standards for blood glucose monitoring systems (BGMSs) according to ISO 15197:2013. Amongst the standards, system accuracy is a major aspect to be considered. The international standard ISO 15197:2013 defines system accuracy as the respective comparison of blood glucose (BG) results obtained with a BGMS and reference analyser with a relevant error range [1]. In addition, such standards states procedures and criteria for the evaluation of system accuracy. In the present study, the system accuracy of two BGMSs (GlucoLAB Auto-coding and Finetest Lite; Infopia Co. Ltd., Anyang, Korea), each with three reagent system lots, was evaluated following ISO 15197:2013. GlucoLAB Auto-coding and Finetest Lite are well-established BGMSs available on the European market since 2011 and 2015 , respectively. Both systems were procured from the manufacturer.
The study was performed in December 2015 and March 2016 at the Endocrine Division, Hanil General Hospital, Seoul, Korea. The study was conducted with institutional review board approval (KMC-2015-ME-003,004). This study followed the international standards regulated by ISO 151597:2013 to verify the accuracy. Precision of the two BGMSs was evaluated using five samples of venous blood from each glucose concentration interval specified following ISO 15197:2013. Results for the CV (\%) fell within the range of 1.9 to $4.9 \%$ (Table 1). System accuracy was evaluated with three reagent system lots from capillary blood samples of 100 different subjects. Two hundred microliters of capillary blood was collected from the fingertips of each subject in lithium heparin tubes. Duplicate measurements of blood samples were performed for each reagent system lot of a BGMS and the collected capillary blood was immediately centrifuged 


\section{Journal of LABORATORY MEDICINE and QUALITY ASSURANCE}

Kyungso Jeon et al $\bullet$ GlucoLab Auto-coding and Finetest Blood Glucose Monitoring System

at 3,500 rpm for 5 minutes. Centrifuged capillary plasma was measured in duplicate with a reference method using Glucose Oxidase-based YSI 2300 STAT PLUS (YSI Life Sciences, Yellow Springs, OH, USA). Respective mean YSI 2300 STAT PLUS results were considered as the reference glucose values. Accuracy and precision of the
YSI 2300 STAT PLUS results were verified during the test procedures [2]. For this purpose, regular internal and external quality control measures were performed as recommended in the manufacturer's manual.

The BGMSs fulfilled the accuracy criteria of ISO 15197:2013, which states at least 95\% of the results

Table 1. Precision of GlucoLAB Auto-coding and Finetest Lite

\begin{tabular}{|c|c|c|c|c|c|c|c|}
\hline \multirow{3}{*}{$\begin{array}{c}\text { ISO 15197:2013 } \\
\text { requirement }(\mathrm{mg} / \mathrm{dL})\end{array}$} & \multirow{3}{*}{ Mean $(\mathrm{mg} / \mathrm{dL})$} & \multicolumn{6}{|c|}{ Repeatability precision (CV \%) } \\
\hline & & \multicolumn{3}{|c|}{ GlucoLAB Auto-coding } & \multicolumn{3}{|c|}{ Finetest Lite } \\
\hline & & Lot 1 & Lot 2 & Lot 3 & Lot 1 & Lot 2 & Lot 3 \\
\hline 30 to 50 & 38.8 & 4.9 & 3.8 & 4.1 & 4.8 & 4.5 & 4.6 \\
\hline 51 to 110 & 86.8 & 2.3 & 2.9 & 2.2 & 2.3 & 2.1 & 1.9 \\
\hline 111 to 150 & 149.5 & 2.3 & 2.0 & 2.2 & 2.3 & 2.6 & 3.2 \\
\hline 151 to 250 & 215.9 & 2.4 & 2.7 & 2.3 & 2.4 & 2.2 & 2.3 \\
\hline 251 to 400 & 352.0 & 2.1 & 2.2 & 1.9 & 1.9 & 2.2 & 2.3 \\
\hline
\end{tabular}

Table 2. System accuracy between GlucoLAB Auto-coding, Finetest Lite BG monitoring systems, and YSI 2300 STAT PLUS Auto analyser $(\mathrm{N}=200)$

\begin{tabular}{|c|c|c|c|c|c|c|c|c|}
\hline \multirow[b]{2}{*}{ BG system } & \multirow{2}{*}{$\begin{array}{l}\text { Strip } \\
\text { lot }\end{array}$} & \multirow{2}{*}{$\begin{array}{c}\text { ISO } \\
\text { 15197:2013 }\end{array}$} & \multicolumn{3}{|c|}{ BG concentration $<100 \mathrm{mg} / \mathrm{dL}$} & \multicolumn{3}{|c|}{ BG concentration $\geq 100 \mathrm{mg} / \mathrm{dL}$} \\
\hline & & & $\begin{array}{c}\text { Within } \pm 15 \\
\mathrm{mg} / \mathrm{dL}\end{array}$ & $\begin{array}{c}\text { Within } \pm 10 \\
\mathrm{mg} / \mathrm{dL}\end{array}$ & $\begin{array}{c}\text { Within } \pm 5 \\
\mathrm{mg} / \mathrm{dL}\end{array}$ & Within $\pm 15 \%$ & Within $\pm 10 \%$ & Within $\pm 5 \%$ \\
\hline \multirow{2}{*}{ GlucoLAB Auto-coding } & Lot 2 & $200(98.5)$ & 100.0 & 98.3 & 72.4 & 97.9 & 89.4 & 58.5 \\
\hline & Lot 3 & $200(98.5)$ & 100.0 & 96.6 & 67.2 & 97.9 & 82.4 & 52.8 \\
\hline \multirow{2}{*}{ Finetest Lite } & Lot 2 & $200(99.0)$ & 100.0 & 100.0 & 71.2 & 98.6 & 84.5 & 49.3 \\
\hline & Lot 3 & $200(97.0)$ & 98.1 & 92.3 & 44.2 & 96.6 & 72.3 & 35.8 \\
\hline
\end{tabular}

Values are presented as number (\%) or \%.

Abbreviation: BG, blood glucose.

Table 3. Consensus error grid analysis of glucose levels measured by GlucoLAB Auto-coding and Finetest Lite BG monitoring system against YSI 2300 STAT PLUS Auto analyser $(\mathrm{N}=200)$

\begin{tabular}{|c|c|c|c|c|c|c|}
\hline \multirow{2}{*}{ BG system } & \multirow{2}{*}{ Strip lot } & \multicolumn{5}{|c|}{ Consensus error grid zone } \\
\hline & & Zone A & Zone B & Zone C & Zone D & Zone E \\
\hline \multirow[t]{3}{*}{ GlucoLAB Auto-coding } & Lot 1 & $200 / 200(100.0)$ & $0 / 200(0)$ & $0 / 200(0)$ & $0 / 200(0)$ & $0 / 200(0)$ \\
\hline & Lot 2 & $198 / 200(99.0)$ & $2 / 200(1.0)$ & $0 / 200(0)$ & $0 / 200(0)$ & $0 / 200(0)$ \\
\hline & Lot 3 & $199 / 200(99.5)$ & $1 / 200(0.5)$ & $0 / 200(0)$ & $0 / 200(0)$ & $0 / 200(0)$ \\
\hline \multirow[t]{3}{*}{ Finetest Lite } & Lot 1 & $200 / 200(100.0)$ & $0 / 200(0)$ & $0 / 200(0)$ & $0 / 200(0)$ & $0 / 200(0)$ \\
\hline & Lot 2 & $200 / 200(100.0)$ & $0 / 200(0)$ & $0 / 200(0)$ & $0 / 200(0)$ & $0 / 200(0)$ \\
\hline & Lot 3 & $200 / 200(100.0)$ & $0 / 200(0)$ & $0 / 200(0)$ & $0 / 200(0)$ & $0 / 200(0)$ \\
\hline
\end{tabular}

Values are presented as number (\%).

Abbreviation: BG, blood glucose. 

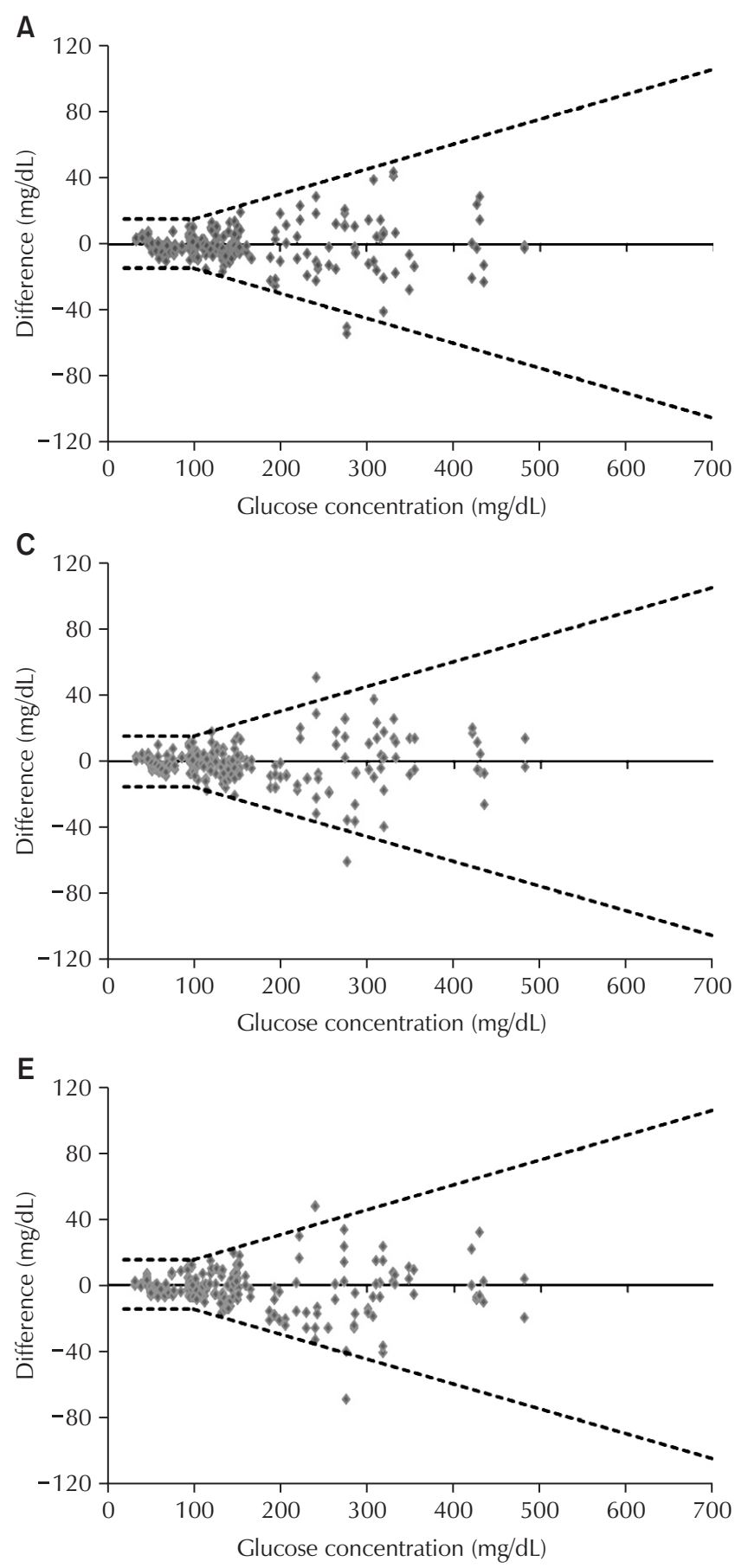

B

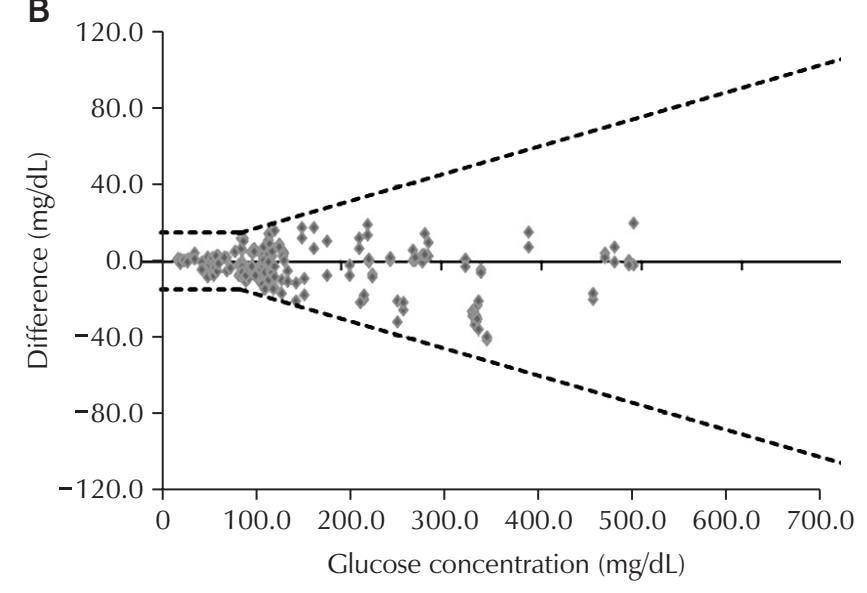

D

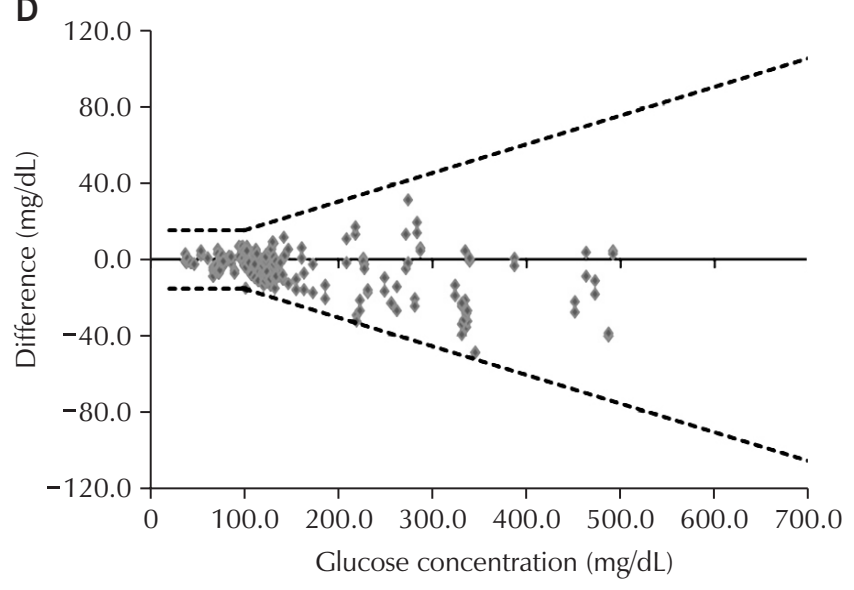

$\mathbf{F}$

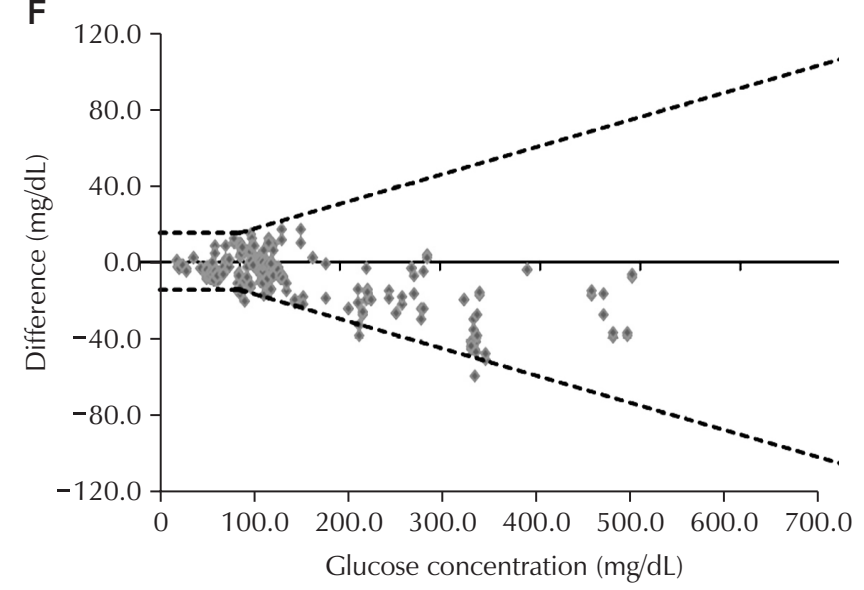

Fig. 1. System accuracy of three lots of two BG monitoring systems. Absolute differences between the BG concentration results measured with the systems and the respective comparison values measured with YSI 2300 STAT PLUS (200 data, duplicate measurements on a sample with each test strip lot) are shown. Solid lines indicate the limits stipulated in ISO 15197:2013. (A) GlucoLAB Auto-coding lot 1. (B) Finetest Lite lot 1. (C) GlucoLAB Auto-coding lot 2. (D) Finetest Lite lot 2. (E) GlucoLAB Autocoding lot 3. (F) Finetest Lite lot 3. Abbreviation: BG, blood glucose. 
Journal of LABORATORY MEDICINE and QUALITY ASSURANCE

Kyungso Jeon et al • GlucoLab Auto-coding and Finetest Blood Glucose Monitoring System

A

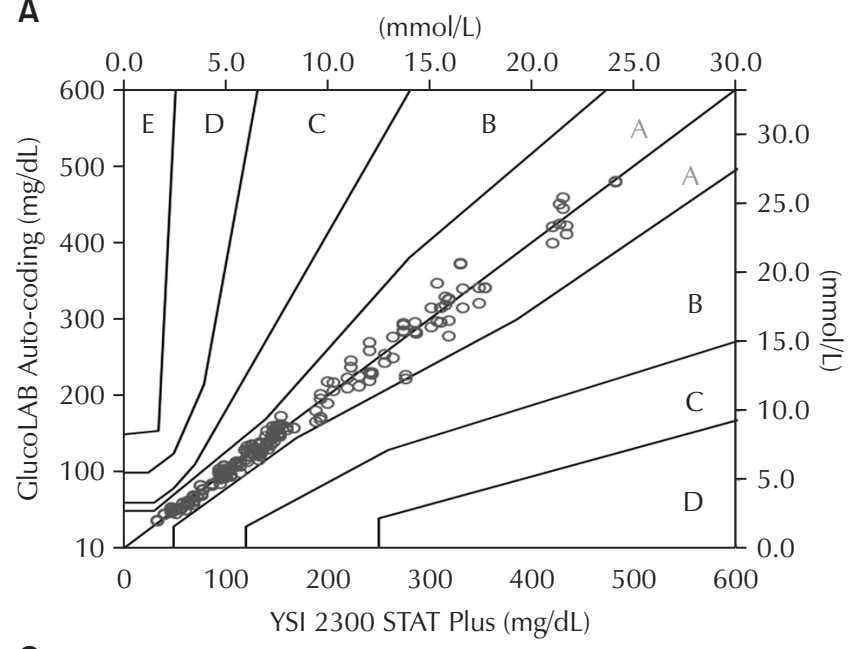

C

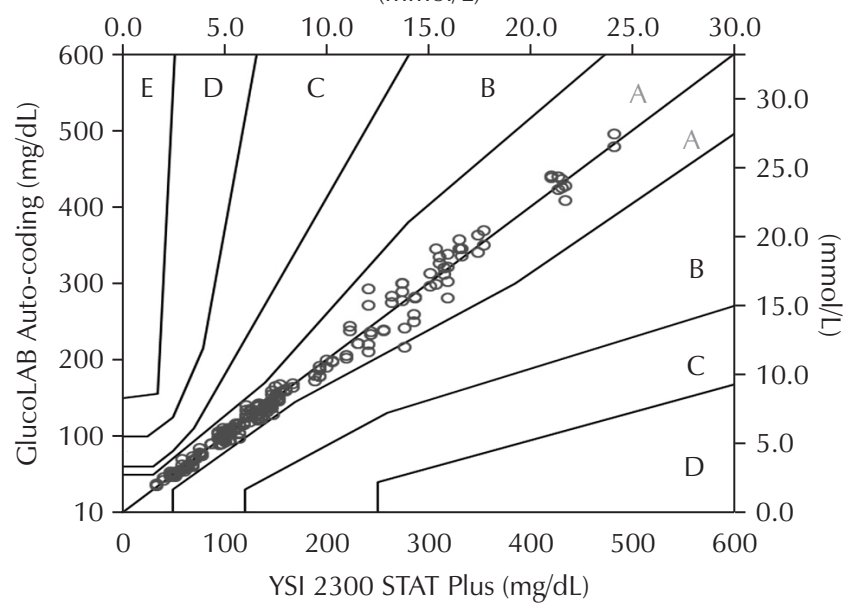

$E$

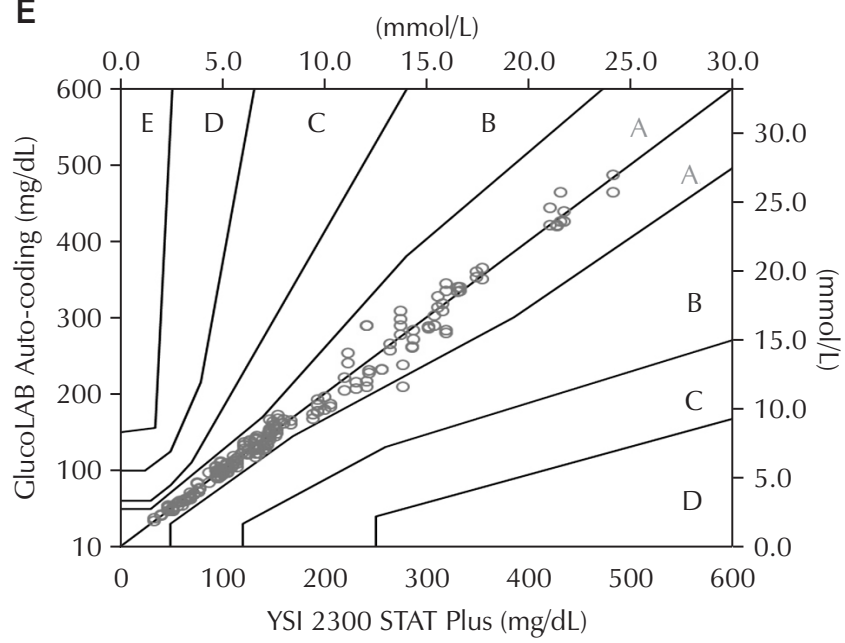

B

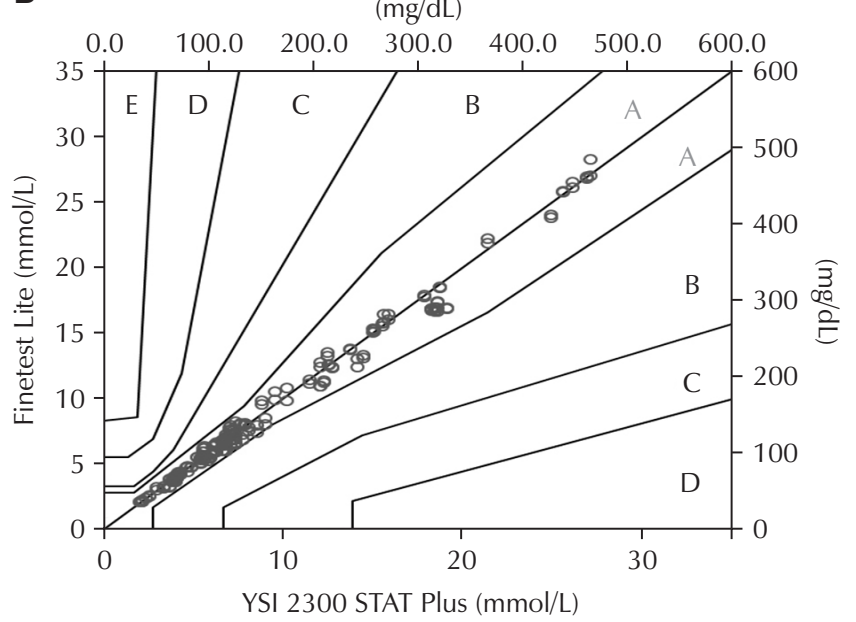

D

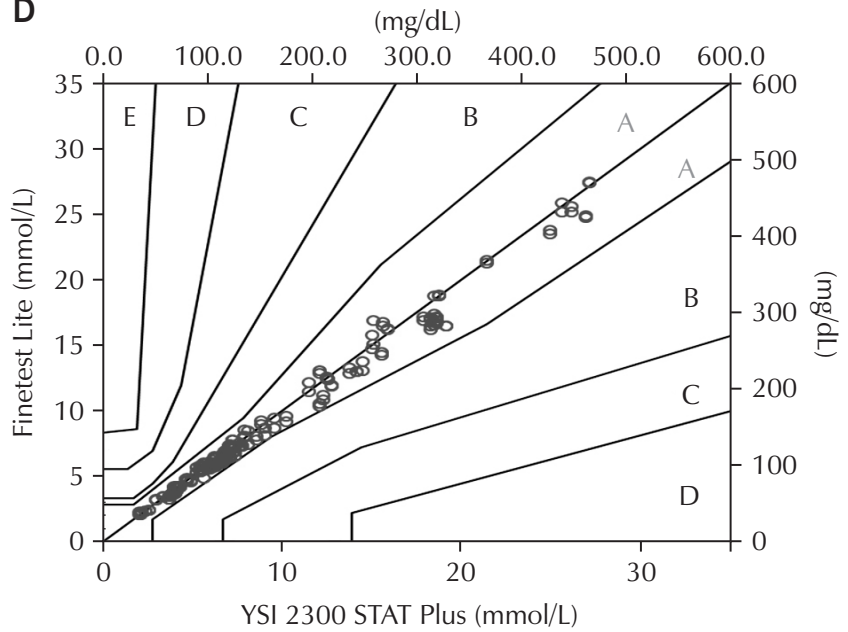

$\mathrm{F}$

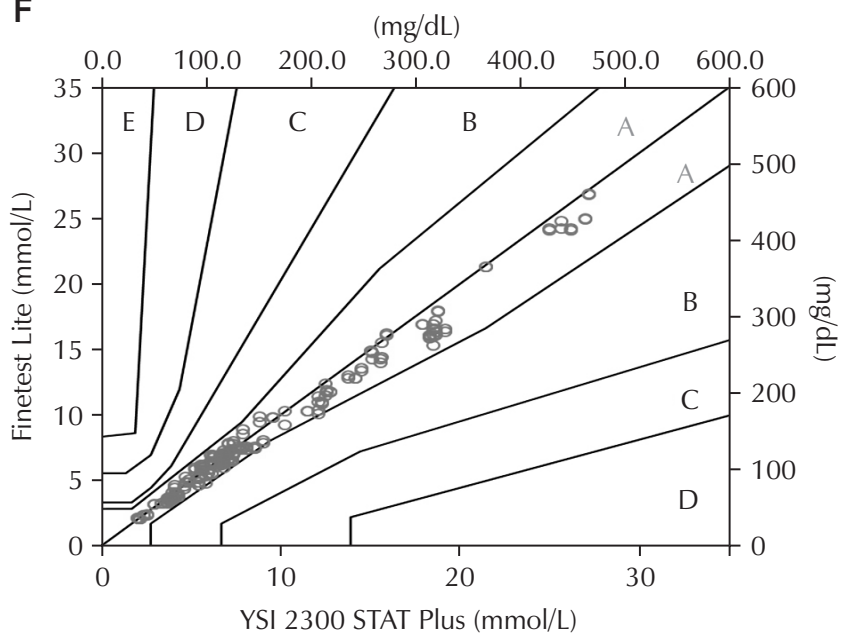

Fig. 2. Consensus error grid analysis of capillary blood glucose results. Each specimen was measured in duplicate by each method. Zone A, clinically accurate (no effect on clinical action); Zone B, clinically acceptable (altered clinical action-little or no effect on clinical outcome); Zone C, altered clinical action-likely to affect clinical outcome; Zone D, altered clinical action-could have significant medical risk; and Zone E, altered clinical action-could have dangerous consequences. (A) GlucoLAB Auto-coding lot 1. (B) Finetest Lite lot 1. (C) GlucoLAB Auto-coding lot 2. (D) Finetest Lite lot 2. (E) GlucoLAB Auto-coding lot 3. (F) Finetest Lite lot 3. 
should be within $\pm 15 \mathrm{mg} / \mathrm{dL}$ of the reference glucose values at $B G$ concentration $<100 \mathrm{mg} / \mathrm{dL}$ and within $\pm 15 \%$ at BG concentrations $\geq 100 \mathrm{mg} / \mathrm{dL}$ (for each individual test strip lot), and at least $99 \%$ of the results of all three lots together were within zones $\mathrm{A}$ and $\mathrm{B}$ of the consensus error grid.

For BG values $<100 \mathrm{mg} / \mathrm{dL}$, the GlucoLAB Auto-coding system showed $100 \%$ of the results within $\pm 15 \mathrm{mg} / \mathrm{dL}$ and 94.8\%-98.3\% within $\pm 10 \mathrm{mg} / \mathrm{dL}$. Finetest Lite showed 98.1\%-100\% within $\pm 15 \mathrm{mg} / \mathrm{dL}$ and $92.3 \%-100 \%$ within $\pm 10 \mathrm{mg} / \mathrm{dL}$. At BG concentrations $\geq 100 \mathrm{mg} / \mathrm{dL}, 97.9 \%-$ 98.6\% of the values measured with the GlucoLAB Autocoding system were within $\pm 15 \%$ and $82.4 \%-89.4 \%$ were within $\pm 10 \%$. For Finetest Lite, 96.6\%-100\% were within $\pm 15 \%$ and $72.3 \%-84.5 \%$ were within $\pm 10 \%$ in these BG concentrations. Considering all BG concentrations, 98.5\%99\% of the GlucoLAB Auto-coding system results and 97\%-100\% of the Finetest Lite results were within the limits (Table 2, Fig. 1). For both systems, 100\% of the values were within zones $\mathrm{A}$ and $\mathrm{B}$ of the consensus error grid (Table 3, Fig. 2).

In this study, GlucoLAB Auto-coding and Finetest Lite fulfilled the system accuracy criteria of ISO 15197:2013 when evaluated against a glucose oxidase-based reference method. GlucoLAB Auto-coding and Finetest Lite BGMSs provided reliable results and satisfied the ISO 15197:2013 accuracy criteria.

\section{ACKNOWLEDGEMENTS}

The authors would like to thank Kim, In Suk and Kim, Sang Won for their helpful participation in this study. This work was supported by Infopia Co. Ltd., Anyang, Korea.

\section{REFERENCES}

1. International Organization for Standardization. In vitro diagnostic test systems requirements for blood-glucose monitoring systems for self-testing in managing diabetes mellitus. ISO 15197:2013 (E).

2. International Organization for Standardization. In vitro diagnostic medical devices measurement of quantities in biological samples metrological traceability of values assigned to calibrators and control materials. EN ISO 17511:2003 (D).

ISO 15197:2013 지침에 따른 자가혈당측정기 GlucoLAB Auto-coding과 Finetest Lite의 시스템 정확도 성능평가 전경소 ${ }^{1} \cdot$ 신미선 $^{2}$

한전의료재단 한일병원 ${ }^{1}$ 진단검사의학과, ${ }^{2}$ 내분비내과

교신저자: 전경소

우)01450 서울시 도봉구 우이천로 308, 한전의료재단 한일병원 진단검사의학과

Tel: 02)901-3720, Fax: 02)901-3606, E-mail: jks3393@hanmail.net

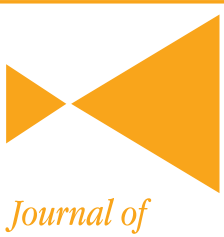

LABORATORY MEDICINE and

QUALITY ASSURANCE 